\title{
The Role of Adjuvant Radiation Therapy in Locally Advanced Bladder Cancer
}

\author{
Gary D. Lewis ${ }^{\mathrm{a}}$, Waqar Haque ${ }^{\mathrm{b}, *}$, Vivek Verma ${ }^{\mathrm{c}}$, E. Brian Butler ${ }^{\mathrm{b}}$ and Bin S. Teh ${ }^{\mathrm{b}}$ \\ ${ }^{a}$ Department of Radiation Oncology, University of Texas Medical Branch, Galveston, TX, USA \\ ${ }^{\mathrm{b}}$ Department of Radiation Oncology, Houston Methodist Hospital, Houston, TX, USA \\ ${ }^{\mathrm{c}}$ Department of Radiation Oncology, Allegheny General Hospital, Pittsburgh, PA, USA
}

\begin{abstract}
.
Background: The standard of care for locally advanced bladder cancer (LABC) is neoadjuvant chemotherapy followed by cystectomy. However, the role of adjuvant therapy for locally advanced bladder cancer is unclear.

Objective: The purpose of this study was to evaluate the outcomes of adjuvant radiation therapy (RT) for patients with LABC, and to determine which risk factors best predict for patients who may best benefit from adjuvant RT.

Methods: The National Cancer Data Base (NCDB) was queried (2004-2013) for patients with newly-diagnosed pT3-4N0$3 \mathrm{M} 0$ urothelial carcinoma of the bladder that received neoadjuvant chemotherapy and cystectomy. Patients were divided into two groups based on the adjuvant therapy they received: RT or observation. Statistics included multivariable logistic regression to determine factors predictive of receiving adjuvant RT, Kaplan-Meier analysis to evaluate overall survival (OS), and Cox proportional hazards modeling to determine variables associated with OS.

Results: Altogether, 1,646 patients met inclusion criteria; 59 (3.6\%) patients received adjuvant RT, while 1,587 (96.4\%) were observed. Patients treated with adjuvant RT were more likely to be female, have positive surgical margins, and receive treatment at a non-academic facility. There was no difference in median overall survival (OS) between patients treated with RT when compared to patients observed (17.7 months vs. 23.5 months; $p=0.085)$. However, an improvement in median OS with the use of adjuvant RT was observed among patients with positive surgical margins (20.3 months vs. 13.1 months; $p=0.032$ ). On multivariate analysis, advancing age, pT4 stage, positive $\mathrm{N}$ stage, positive margins, and lower socioeconomic status were associated with worse OS.

Conclusions: In the largest study to date evaluating efficacy of adjuvant radiotherapy in patients with locally advanced bladder cancer, use of RT was not associated with OS in all patients, while RT was associated with improvemed OS among patients with positive surgical margins. Prospective studies are recommended to confirm these findings.
\end{abstract}

Keywords: Bladder cancer, cystectomy, radiotherapy

\section{INTRODUCTION}

After prostate cancer, bladder cancer is the most common neoplasm of the genitourinary tract in the United States and results in the deaths of approxi-

\footnotetext{
${ }^{*}$ Correspondence to: Waqar Haque, MD, Department of Radiation Oncology, Houston Methodist Hospital, Cancer Center and Research Institute, Houston, TX 77030, USA. Tel.: +1 932522 2873; Fax: +1 713441 4493; E-mail: waqarh786@gmail.com.
}

mately 15,000 patients per year [1]. Of all bladder cancer patients, $25 \%$ present with muscle-invasive disease, for which radical cystectomy has long been the cornerstone of definitive management and is currently a standard of care $[2,3]$. Although survival outcomes are reasonable ( $60 \%$ at 5 years) for organconfined, muscle-invasive disease (pT2), survival outcomes are worse $(10-50 \%$ at 5 years for $>\mathrm{pT} 3$ disease) for patients with more advanced disease, 
with a high rate of distant metastasis [4]. Consequently, systemic chemotherapy has been used to improve outcomes for these patients, with level one evidence supporting its use in the neoadjuvant setting $[3,5]$.

However, there is growing concern about the importance of locoregional control for locally advanced bladder cancer (LABC). Historically, the rate of pelvic failure for $\mathrm{LABC}$ after radical cystectomy was thought to be low; early surgical literature reported locoregional recurrence rates on the order of $7-13 \%$ [6-8]. These low reported rates are likely due to the absence of routine use of advanced imaging of the pelvis during follow-up $[6,7]$ as well as the lack of reporting pelvic failure if they were synchronous with distant metastases $[9,10]$. More recent data suggests that the rate of locoregional recurrence for patients undergoing cystectomy can be as high as $58 \%$, with local failure rates of up to $72 \%$ for patients with $\mathrm{pT} 4 \mathrm{pN} 1$ disease $[11,12]$. Other studies have demonstrated that that locoregional recurrence independently predicts for distant metastasis and worse disease-specific survival, leading authors to advocate for adjuvant therapy in patients with high risk bladder cancer at high risk for local failure $[13,14]$.

As a result, there may be a role for local therapy with adjuvant radiotherapy (RT) to improve local control, consequently enhancing survival outcomes [15]. A randomized trial by Zaghloul et al. comparing postoperative radiotherapy to observation after cystectomy for patients with LABC in Egypt reported both a disease-free survival benefit and local control benefit with radiotherapy, albeit in the setting of no systemic therapy [16]. A follow-up phase II trial by the same group demonstrated a substantial local control benefit and marginal disease free survival benefit with the addition of radiation therapy (RT) to adjuvant chemotherapy following cystectomy [17]. To further elucidate the role of adjuvant RT for patients with LABC, clinical trials addressing this question are either currently accruing or in development in France (GETUG-AFU), the United Kingdom (NCRI), National Cancer Institution (NCI) Cairo, Belgium (University of Ghent), and India (Tata Memorial Hospital) [15]. Given this interest, we aimed to examine if post-operative radiotherapy is associated with improved survival outcomes in patients with LABC urothelial carcinoma of the bladder who received neoadjuvant chemotherapy and underwent radical cystectomy using the National Cancer Data Base (NCDB).

\section{MATERIALS AND METHODS}

This investigation analyzed the NCDB, which is a joint project of the Commission on Cancer $(\mathrm{CoC})$ of the American College of Surgeons and the American Cancer Society, which consists of de-identified information regarding tumor characteristics, patient demographics, and patient survival for approximately $70 \%$ of the US population [18-20]. The NCDB contains information not included in the Surveillance, Epidemiology, and End Results database, including details regarding use of systemic therapy and radiation dose. The data used in the study were derived from a de-identified NCDB file. The American College of Surgeons and the $\mathrm{CoC}$ have not verified and are neither responsible for the analytic or statistical methodology employed nor the conclusions drawn from these data by the investigators. As all patient information in the NCDB database is de-identified, this study was exempt from institutional review board evaluation.

The most recently released NCDB dataset corresponded to the years 2004-2013. Inclusion criteria for this study involved patients age $\geq 18$ with urothelial carcinoma of the bladder treated with neoadjuvant chemotherapy and cystectomy and found to have pT3/4pN0-3M0 disease. We opted to include solely patients with pT3/4pN0-3M0 disease based on inclusion criteria similar to randomized trials attempting to address the role of adjuvant RT for LABC [15]. Additionally, for inclusion, patients required histological diagnostic confirmation, definitive treatment with neoadjuvant chemotherapy and cystectomy (surgical procedure of the primary site codes 50, 60-64, 70-74, 80), and a recorded vital status. Patients treated with adjuvant chemotherapy or neoadjuvant RT were excluded from this analysis, because based on current national guidelines, there is no solid indication for neoadjuvant RT for adjuvant chemotherapy if neoadjuvant chemotherapy is given [21]. Patients were divided into two cohorts: those receiving adjuvant RT and those observed following surgery. Using a classification scheme from other published studies utilizing the NCDB, an academic facility was defined as an institution with both an accession of more than 500 newly diagnosed cancer cases per year and one that provided postgraduate medical education in at least four program areas, including internal medicine and general surgery [22]. All other facilities, including Comprehensive Community Cancer Programs, Community Cancer Programs, and Integrated Network Programs, were categorized as non-academic, 
as none of these institutions require graduate medical education.

Information collected on each patient included demographic data, comorbidity information, clinicopathologic tumor parameters, and treatment facility characteristics. All statistical tests were two-sided, with a threshold of $p<0.05$ for statistical significance, and were performed using STATA (version 14, College Station, TX). Fisher's exact or $\chi 2$ test analyzed categorical proportions between groups in the non-parametric and parametric settings, respectively. Univariable and multivariable logistic regression modeling was utilized to determine characteristics that were predictive for receipt of RT. Factors for inclusion in the multivariate analysis were those found to be statistically significant on univariate analysis. The Kaplan-Meier method was used for survival analysis while performing a landmark analysis, in which patients dying within 6 months of diagnosis were excluded to account for immortal time bias, and comparisons between the two treatment paradigms were performed with the log-rank test for all patients. Subset analysis was performed while stratifying patients by $\mathrm{T}$ stage, $\mathrm{N}$ stage, and surgical margin status, based on data demonstrating that these factors were predictive of local recurrence for patients with urothelial carcinoma following cystectomy [23]. Overall survival (OS) was defined as the interval between the date of diagnosis and the date of death or last contact. Multivariate Cox proportional hazards modeling was additionally used to identify variables associated with OS in the entire cohort. Patients included in the multivariate analysis were those found to be statistically significant on univariate analysis. Multivariate cox proportional hazards modeling was subsequently performed on the subset of patients with positive margins.

\section{RESULTS}

A complete flow diagram of patient selection is provided in Fig. 1. In total, 1,646 patients met inclusion criteria. Of these, 59 (3.6\%) patients received adjuvant RT, while 1,587 (96.4\%) patients were observed. A greater proportion of patients that received adjuvant RT had pT4 disease, positive margins, and received treatment at a non-academic facility. Table 1 displays the demographic and clinical characteristics of the analyzed patients. The majority of patients were male, Caucasian, and had a CharlsonDeyo comorbidity score of 0 .

Multivariable logistic regression analysis was performed to evaluate factors independently associated with receiving adjuvant RT. Patients treated with adjuvant RT were more likely to be female, have positive surgical margins, and receive treatment at a non-academic facility. These factors are summarized in Table 2.

The median follow up time was 19.5 months (interquartile range, 11.7-32.9 months) KaplanMeier curves are displayed in Fig. 2. In the whole

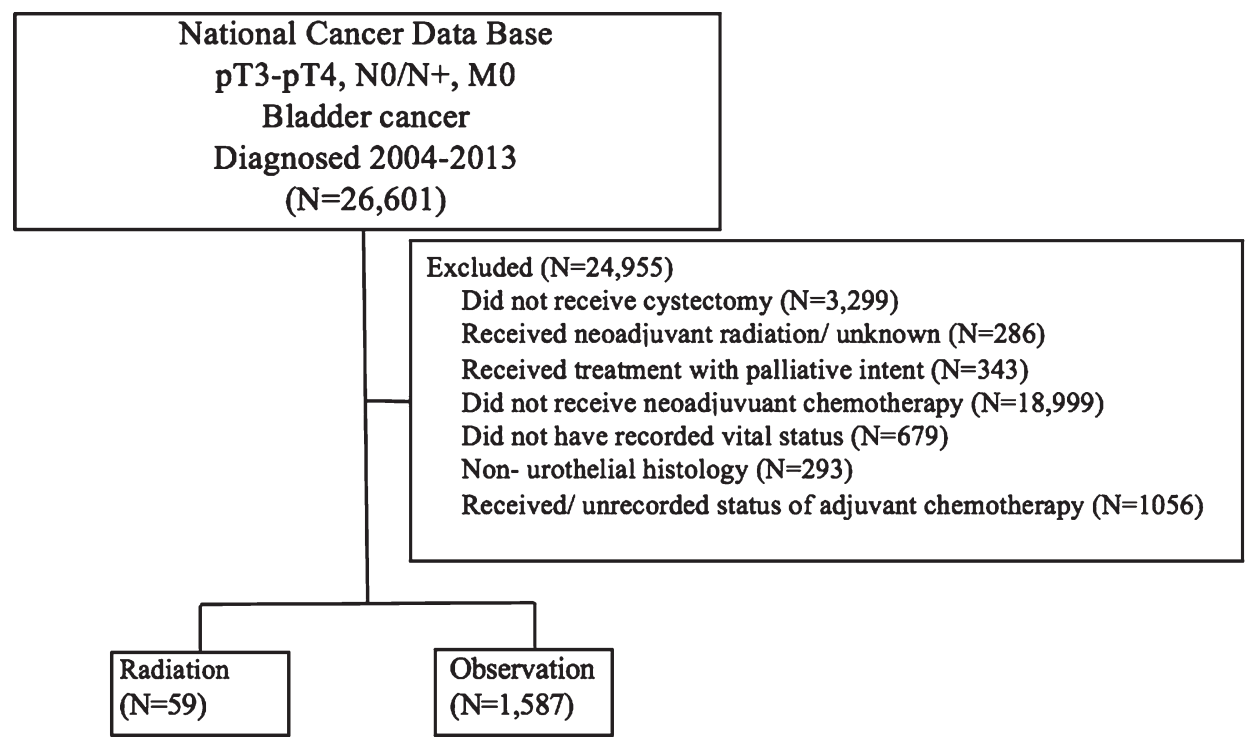

Fig. 1. Patient selection diagram. 
Table 1

Baseline characteristics of patients in each of the four cohorts

\begin{tabular}{|c|c|c|c|}
\hline Characteristic & $\begin{array}{c}\text { Adjuvant radiation; } \\
n=59(\%)\end{array}$ & $\begin{array}{l}\text { Observation; } \\
n=1587(\%)\end{array}$ & $P$ value \\
\hline \multicolumn{4}{|l|}{$\overline{\text { Age }}$} \\
\hline$<65$ & $25(42.4 \%)$ & $656(41.3 \%)$ & \multirow[t]{3}{*}{0.953} \\
\hline $65-74$ & $23(39.0 \%)$ & $609(38.4 \%)$ & \\
\hline $75+$ & $11(18.6 \%)$ & $322(20.3 \%)$ & \\
\hline \multicolumn{4}{|l|}{ Sex } \\
\hline Male & $37(62.7 \%)$ & $1196(75.4 \%)$ & \multirow[t]{2}{*}{0.028} \\
\hline Female & $22(37.3 \%)$ & $391(24.6 \%)$ & \\
\hline \multicolumn{4}{|l|}{ Race } \\
\hline White & $51(86.4 \%)$ & $1409(88.9 \%)$ & \multirow[t]{4}{*}{0.024} \\
\hline African American & $3(5.1 \%)$ & $96(6.1 \%)$ & \\
\hline Hispanic & $5(8.5 \%)$ & $39(2.5 \%)$ & \\
\hline Other & $0(0.0 \%)$ & $43(2.7 \%)$ & \\
\hline \multicolumn{4}{|l|}{ pT Stage } \\
\hline $\mathrm{T} 3$ & $27(45.8 \%)$ & $1112(70.1 \%)$ & \multirow[t]{2}{*}{$<0.0001$} \\
\hline $\mathrm{T} 4$ & $32(54.2 \%)$ & $475(29.9 \%)$ & \\
\hline \multicolumn{4}{|l|}{ pN Stage } \\
\hline NO & $26(44.1 \%)$ & $907(57.2 \%)$ & \multirow[t]{4}{*}{0.086} \\
\hline N1 & $10(17.0 \%)$ & $263(16.6 \%)$ & \\
\hline $\mathrm{N} 2$ & $18(30.5 \%)$ & $358(22.6 \%)$ & \\
\hline N3 & $5(8.5 \%)$ & $59(3.7 \%)$ & \\
\hline \multicolumn{4}{|l|}{ Margin status } \\
\hline Negative & $26(44.1 \%)$ & $1284(80.9 \%)$ & \multirow[t]{3}{*}{$<0.0001$} \\
\hline Positive & $30(50.9 \%)$ & $244(15.4 \%)$ & \\
\hline Not recorded & $3(5.1 \%)$ & $59(3.7 \%)$ & \\
\hline \multicolumn{4}{|l|}{ Charlson Deyo Score } \\
\hline 0 & $46(78.0 \%)$ & $1138(71.7 \%)$ & \multirow[t]{3}{*}{0.390} \\
\hline 1 & $9(15.3 \%)$ & $361(22.8 \%)$ & \\
\hline 2 & $4(6.8 \%)$ & $88(5.6 \%)$ & \\
\hline \multicolumn{4}{|l|}{ Facility Type } \\
\hline Academic & $23(39.0 \%)$ & $952(60.0 \%)$ & \multirow[t]{3}{*}{0.004} \\
\hline Non academic & $36(61.0 \%)$ & $626(39.5 \%)$ & \\
\hline Not recorded & $0(0.0 \%)$ & $(0.6 \%)$ & \\
\hline \multicolumn{4}{|l|}{ Insurance } \\
\hline Medicaid & $3(5.1 \%)$ & $73(4.6 \%)$ & \multirow[t]{5}{*}{0.697} \\
\hline Private & $22(37.3 \%)$ & $581(36.6 \%)$ & \\
\hline Medicare & $33(55.9 \%)$ & $839(52.9 \%)$ & \\
\hline Not insured & $1(1.7 \%)$ & $46(2.9 \%)$ & \\
\hline Other & $0(0.0 \%)$ & $48(3.0 \%)$ & \\
\hline \multicolumn{4}{|l|}{ Income } \\
\hline$<\$ 47999$ & $26(44.1 \%)$ & $600(37.8 \%)$ & \multirow[t]{3}{*}{0.247} \\
\hline$\$ 48000+$ & $31(52.5 \%)$ & $965(60.8 \%)$ & \\
\hline Not recorded & $2(3.4 \%)$ & $22(1.4 \%)$ & \\
\hline
\end{tabular}

cohort, there was no difference in median overall survival (OS) between patients treated with RT when compared to patients observed (17.7 months vs. 23.4 months; $p=0.085$ ). However, on subset analysis, an improvement in median OS with adjuvant RT was observed among patients with positive surgical margins (20.3 months vs. 13.1 months; $p=0.032$ ), though there was no difference in OS with adjuvant RT use for patients with N2-N3 disease (16.6 months vs. 15.1 months, $p=0.205$ ) or pT4 disease ( 18.5 months vs. 16.7 months, $p=0.5728$ ).

On multivariate analysis (Table 3 ), advancing age, pT4 stage, positive N stage, positive surgical margins, receipt of treatment at a non-academic facility, and lower socioeconomic status were associated with worse OS. Multivariate analysis amongst patients specifically with positive margins confirmed (supplemental Table 1) that adjuvant RT was associated with improved OS when accounting for confounding variables (Hazard ratio $=0.474,95 \%$ confidence interval $0.281-0.801, p=0.005)$.

\section{DISCUSSION}

Given the lack of clear evidence to guide adjuvant management for LABC, the current study provides 
Table 2

Characteristics predictive for receipt of radiation therapy on multivariable logistic regression analysis

\begin{tabular}{|c|c|c|c|}
\hline Characteristic & Odds Ratio & $\begin{array}{l}\text { 95\% Confidence } \\
\text { Interval }\end{array}$ & $P$ value \\
\hline \multicolumn{4}{|l|}{ Age } \\
\hline$<65$ & \multicolumn{2}{|c|}{1 (reference) } & \\
\hline $65-74$ & 0.693 & $0.294-1.630$ & 0.400 \\
\hline $75+$ & 0.522 & $0.190-1.435$ & 0.208 \\
\hline \multicolumn{4}{|l|}{ Sex } \\
\hline Male & \multicolumn{2}{|c|}{1 (reference) } & \\
\hline Female & 1.785 & $1.010-3.154$ & 0.046 \\
\hline \multicolumn{4}{|l|}{ Race } \\
\hline White & \multicolumn{2}{|c|}{1 (reference) } & \\
\hline African American & 0.741 & $0.216-2.536$ & 0.633 \\
\hline Hispanic & 3.331 & $1.109-10.007$ & 0.032 \\
\hline Other & - & - & - \\
\hline \multicolumn{4}{|l|}{ pT Stage } \\
\hline T3 & \multicolumn{2}{|c|}{1 (reference) } & \\
\hline $\mathrm{T} 4$ & 1.723 & 0.958-3.099 & 0.069 \\
\hline \multicolumn{4}{|l|}{ pN Stage } \\
\hline N0 & \multicolumn{2}{|c|}{1 (reference) } & \\
\hline N1 & 1.263 & $0.584-2.730$ & 0.553 \\
\hline $\mathrm{N} 2$ & 1.256 & $0.650-2.427$ & 0.499 \\
\hline N3 & 1.858 & $0.632-5.462$ & 0.260 \\
\hline \multicolumn{4}{|l|}{ Margin status } \\
\hline Negative & \multicolumn{2}{|c|}{1 (reference) } & \\
\hline Positive & 4.671 & $2.537-8.602$ & $<0.0001$ \\
\hline Not recorded & 2.325 & $0.648-8.349$ & 0.196 \\
\hline \multicolumn{4}{|l|}{ Charlson Deyo Score } \\
\hline 0 & \multicolumn{2}{|c|}{1 (reference) } & \\
\hline 1 & 0.629 & $0.296-1.338$ & 0.229 \\
\hline 2 & 0.994 & $0.333-2.963$ & 0.991 \\
\hline \multicolumn{4}{|l|}{ Facility Type } \\
\hline Academic & \multicolumn{2}{|c|}{1 (reference) } & \\
\hline Non academic & 2.259 & $1.286-3.968$ & 0.005 \\
\hline Not recorded & - & - & - \\
\hline \multicolumn{4}{|l|}{ Insurance } \\
\hline Medicaid & \multicolumn{2}{|c|}{1 (reference) } & \\
\hline Private & 1.242 & $0.328-4.698$ & 0.750 \\
\hline Medicare & 1.968 & $0.446-8.675$ & 0.371 \\
\hline Not insured & 0.540 & $0.049-5.990$ & 0.616 \\
\hline Other & - & - & - \\
\hline \multicolumn{4}{|l|}{ Income } \\
\hline$<\$ 47999$ & \multicolumn{2}{|c|}{1 (reference) } & \\
\hline$\$ 48000+$ & 0.813 & $0.463-1.427$ & 0.470 \\
\hline Not recorded & 1.455 & $0.284-7.469$ & 0.653 \\
\hline
\end{tabular}

important information regarding the utility of adjuvant RT for patients in this patient population. To our knowledge, this is the largest study to date examining the use, role, and benefit of adjuvant RT for patients with $\mathrm{LABC}$ undergoing treatment with neoadjuvant chemotherapy and radical cystectomy in which some of the patients received adjuvant therapy. Several observations can be made from our analysis. First, in accordance with the existing literature, observation is the most common management strategy after neoadjuvant chemotherapy and cystectomy. Second, adjuvant RT was more likely to be in the setting of positive margins and in patients treated at non-academic centers. Third, though there were no differences in OS with adjuvant RT, an improvement in OS was observed among patients with positive margins.

As noted earlier, the randomized controlled trial by Zaghloul et al. found an improvement in disease-free survival and local control with radiotherapy as compared to cystectomy alone [16]. However, since the trial was conducted in Egypt, the majority of patients in the study had squamous cell carcinoma histology, and its results may not be applicable to patients with bladder cancer in the U.S., who have primarily urothelial carcinoma. A second randomized trial by the same group compared adjuvant chemotherapy and RT to adjuvant chemotherapy alone in patients with high- risk bladder cancer following cystectomy 
A
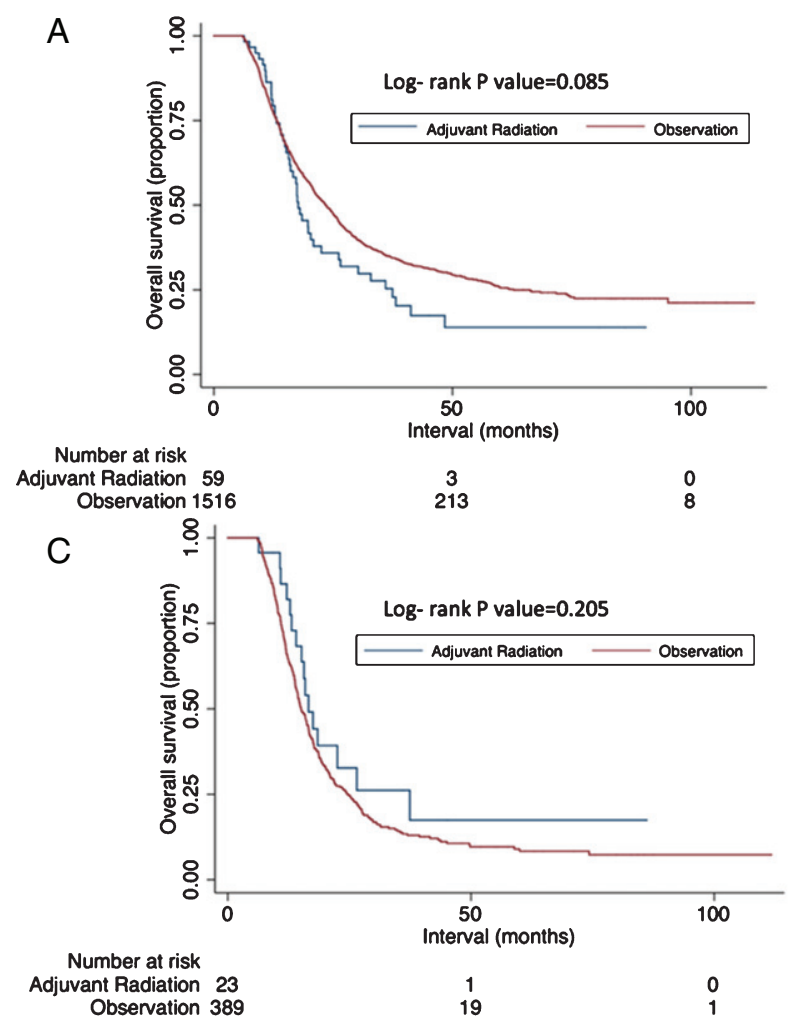

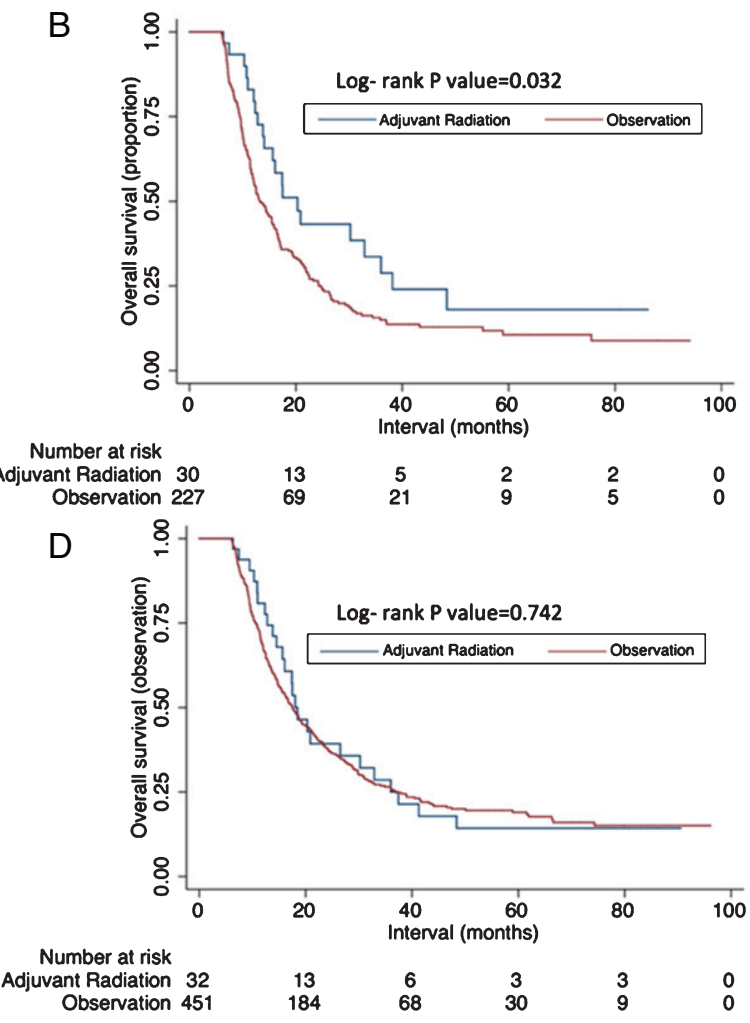

Fig. 2. Kaplan-Meier overall survival curves comparing those receiving chemoradiation versus observation for all patients (A); among surgical margin positive patients (B); among pN2- 3 patients (C); among pT4 patients (D).

and demonstrated improved local control and disease free survival with the use of RT [17]. Only $47 \%$ of the patients in this study had squamous cell carcinoma, whereas $53 \%$ had urothelial carcinoma, so these results may be applicable to patients with bladder cancer in the U.S. However, in each of the aforementioned trials, patients did not receive neoadjuvant chemotherapy, so the efficacy of RT may have been partially due to the lack of systemic therapy. To eliminate these confounding factors in our study, we focused specifically on patients with urothelial carcinoma who received standard of care therapy with neoadjuvant chemotherapy followed by radical cystectomy.

The present results suggest patients with positive surgical margins may have an OS benefit with the use of adjuvant RT. This may be since the goal of adjuvant $\mathrm{RT}$ is to eradicate residual disease. The importance of adjuvant RT in patients with positive surgical margins appears to be relatively well understood; while only $3.6 \%$ of all patients included in the president study received adjuvant $\mathrm{RT}$, among patients with positive surgical margins, the proportion of patients receiving RT increased to $10.9 \%$.
Although RT may not be necessary for all patients in adjuvant setting, there are likely to be high-risk patients that do derive a benefit. In an attempt to better select patients who may benefit most from adjuvant RT, researchers have attempted to determine risk factors for pelvic recurrence. Baumann et al. developed a risk stratification model based on a cohort of 442 consecutive cystectomy patients and found that $\geq$ pT3 stage, number of nodes excised ( $<10 \mathrm{vs.} \geq 10$ ), and surgical margin status were significant independent predictors of local failure [23]. However, other investigators have determined that only pT- stage and $\mathrm{pN}$-stage are significant predictors of local failure [12]. In the present study, we opted not to examine number of nodes excised as this has not been validated in multiple studies and since a significant proportion of these values were missing in the NCDB.

Our analysis did not find an OS benefit with adjuvant RT in pN2-3 disease or higher T-stage (pT4) disease. This is may be due to the relatively small number of patients receiving radiotherapy in our analysis. Though a trend to an OS benefit with the addition of adjuvant RT in patients with N2-N3 disease was observed in the present investigation (16.6 months vs 
Table 3

Cox univariate and multivariate analysis of factors predictive of overall survival in the entire cohort

\begin{tabular}{|c|c|c|c|c|c|c|}
\hline Characteristic & $\begin{array}{c}\text { Hazard Ratio- } \\
\text { Univariate analysis }\end{array}$ & $\begin{array}{l}\text { 95\% Confidence } \\
\text { Interval } \\
\end{array}$ & $P$ value & $\begin{array}{c}\text { Hazard Ratio- } \\
\text { Multivariate analysis }\end{array}$ & $\begin{array}{l}\text { 95\% Confidence } \\
\text { Interval } \\
\end{array}$ & $P$ value \\
\hline \multicolumn{7}{|l|}{ Treatment } \\
\hline Observation & \multicolumn{2}{|c|}{1 (reference) } & & - & - & - \\
\hline Adjuvant radiation & 1.222 & $0.906-1.647$ & 0.180 & - & - & - \\
\hline \multicolumn{7}{|l|}{ Age } \\
\hline$<65$ & \multicolumn{2}{|c|}{1 (reference) } & \multicolumn{4}{|c|}{1 (reference) } \\
\hline $65-74$ & 1.142 & $0.998-1.306$ & 0.053 & 1.130 & $0.987-1.294$ & 0.077 \\
\hline $75+$ & 1.289 & $1.100-1.511$ & 0.002 & 1.247 & $1.02-1.463$ & 0.007 \\
\hline \multicolumn{7}{|l|}{ Sex } \\
\hline Male & \multicolumn{2}{|c|}{1 (reference) } & & - & - & - \\
\hline Female & 1.023 & $0.892-1.173$ & 0.743 & - & - & - \\
\hline \multicolumn{7}{|l|}{ Race } \\
\hline White & \multicolumn{2}{|c|}{1 (reference) } & & - & - & - \\
\hline African American & 1.118 & $0.880-1.420$ & 0.363 & - & - & - \\
\hline Hispanic & 0.996 & $0.605-1.399$ & 0.538 & - & - & - \\
\hline Other & 0.704 & $0.466-1.065$ & 0.097 & - & - & - \\
\hline \multicolumn{7}{|l|}{ pT Stage } \\
\hline $\mathrm{T} 3$ & \multicolumn{2}{|c|}{1 (reference) } & \multicolumn{4}{|c|}{1 (reference) } \\
\hline T4 & 1.508 & $0.330-1.708$ & $<0.0001$ & 1.245 & $1.091-1.421$ & 0.001 \\
\hline \multicolumn{7}{|l|}{ pN Stage } \\
\hline NO & \multicolumn{2}{|c|}{1 (reference) } & \multicolumn{4}{|c|}{1 (reference) } \\
\hline N1 & 1.422 & $1.204-1.681$ & $<0.0001$ & 1.447 & $1.223-1.711$ & $<0.0001$ \\
\hline $\mathrm{N} 2$ & 2.332 & $2.025-2.684$ & $<0.0001$ & 2.112 & $1.825-2.444$ & $<0.0001$ \\
\hline N3 & 2.785 & $2.085-3.729$ & $<0.0001$ & 2.602 & $1.941-3.488$ & $<0.0001$ \\
\hline \multicolumn{7}{|l|}{ Margin status } \\
\hline Negative & \multicolumn{2}{|c|}{1 (reference) } & \multicolumn{4}{|c|}{1 (reference) } \\
\hline Positive & 2.005 & $1.729-2.326$ & $<0.0001$ & 1.553 & $1.27-1.817$ & $<0.0001$ \\
\hline Not recorded & 1.085 & $0.95-1.479$ & 0.608 & 0.933 & $0.682-1.276$ & 0.664 \\
\hline \multicolumn{7}{|l|}{ Charlson Deyo Score } \\
\hline 0 & \multicolumn{2}{|c|}{1 (reference) } & & - & - & - \\
\hline 1 & 1.139 & $0.989-1.311$ & 0.070 & - & - & - \\
\hline 2 & 1.205 & $0.934-1.556$ & 0.152 & - & - & - \\
\hline \multicolumn{7}{|l|}{ Facility Type } \\
\hline Academic & \multicolumn{2}{|c|}{1 (reference) } & \multicolumn{4}{|c|}{1 (reference) } \\
\hline Non academic & 1.210 & $1.073-2.364$ & 0.002 & 1.258 & $1.113-1.421$ & $<0.0001$ \\
\hline Not recorded & 0.917 & $0.380-2.212$ & 0.847 & 0.792 & $0.36-1.930$ & 0.609 \\
\hline Insurance & & & & & & \\
\hline Medicaid & 1 (refe & nce) & & - & - & - \\
\hline Private & 0.808 & $0.602-1.085$ & 0.157 & - & - & - \\
\hline Medicare & 0.937 & $0.70-1.251$ & 0.660 & - & - & - \\
\hline Not insured & 0.726 & $0.457-1.153$ & 0.175 & - & - & - \\
\hline Other & 0.868 & $0.557-1.353$ & 0.531 & - & - & - \\
\hline Income & & & & & & \\
\hline$<\$ 47999$ & 1 (refe & nce) & & 1 (refer & ce) & \\
\hline$\$ 48000+$ & 0.810 & $0.716-0.915$ & 0.001 & 0.820 & $0.725-0.927$ & 0.001 \\
\hline Not recorded & 2.204 & $1.422-3.417$ & $<0.0001$ & 2.197 & $1.413-3.417$ & $<0.0001$ \\
\hline
\end{tabular}

14.5 months, $p=0.1283$ ), this did not achieve statistical significance. Given that only 23 patients with N2-N3 disease received RT, as well as the significant imbalance in terms of negative prognostic factors in the two treatment arms, it is possible that with greater patient numbers, an OS would have been statistically significant. A survey of US radiation oncologists found nearly half $(46 \%)$ had used adjuvant RT, so the low numbers of patients receiving RT in our study are somewhat surprising [24]. On the other hand, the US-based NRG-GU001 trial investigating the role of adjuvant RT closed due to poor accrual, suggesting a lack of robust referral patterns. Our study also did not have information on the radiation fields for the patients receiving adjuvant RT. Patterns of failure studies indicate that the iliac/obturator nodal beds common sites of pelvic recurrence in patients with negative margins and the presacral nodes and cystectomy are more common failure sites in patients with positive margins [25]. Another possible explanation for the lack of survival benefit seen in our study for patients with pN2-3 disease or T4 disease 
may be inadequate RT coverage of regions most at risk for recurrence. A recently published consensus contouring atlas for adjuvant bladder RT may help with standardization of target delineation for management of future patients and may lead to further improvements in patients treated with adjuvant RT [26]. A multi-institutional study from France has demonstrated good local control for patients with bladder cancer treated with adjuvant RT [27]. The authors reported using the Radiation Therapy Oncology Group (RTOG) atlas as a guide to define the Clinical Target Volume, suggesting that using published guidelines for target delineation can result in good clinical outcomes.

There are several limitations in our study due to its reliance on the NCDB. First, the retrospective nature of the study and all associated inherent biases must be acknowledged. Second, the NCDB does not keep track of several noteworthy variables, such as reasons for a particular treatment, radiation treatment fields, receipt of targeted therapies, and salvage treatments. In addition, the NCDB does not record other endpoints such as tolerance of therapy, cancer-specific survival, and local/regional control, which are important variables when assessing the utility of additional therapy. Moreover, patients treated with adjuvant chemotherapy were excluded from this study, suggesting that we do not know the role of adjuvant radiotherapy in patients in addition to adjuvant concurrent/sequential chemotherapy. While this study was not designed to determine the efficacy of adjuvant chemotherapy after neoadjuvant chemotherapy and cystectomy, there may be potential benefits for high risk patients [28, 29]; additional research is needed to further explore this question. Overall, these limitations do not diminish the need for further investigations of the role of adjuvant therapy for LABC.

\section{CONCLUSIONS}

Adjuvant RT following neoadjuvant chemotherapy and radical cystectomy was not associated with improved OS in a general LABC cohort. However, an improvement in OS was observed among patients with positive margins. On multivariate analysis, advancing age, pT4 stage, positive $\mathrm{N}$ stage, positive margins, and lower socioeconomic status were associated with worse overall survival. This study is the largest study of adjuvant radiotherapy to date, and our findings highlight the need for additional prospective data; we eagerly await the results of the currently ongoing clinical trials on this topic.

\section{DECLARATION}

There are no acknowledgements. There was no funding for this study. This study has not been presented or published in part or full form elsewhere. All authors declare no conflicts of interest.

\section{DISCLAIMERS}

None. This has never been presented/published before in any form. All authors declare that conflicts of interest do not exist.

\section{FUNDING}

There was no research support for this study.

\section{SUPPLEMENTARY MATERIAL}

The supplementary material is available in the electronic version of this article: http://dx.doi. org/10.3233/BLC-180163.

\section{REFERENCES}

[1] Siegel RL, Miller KD, Jemal A. Cancer statistics, 2015. CA: A Cancer Journal for Clinicians. 2015;65:5-29.

[2] Howlander N, Noone AM, Krapcho M, et al. Seer cancer statistics review, 1975-2009 (vintage 2009 populations). Bethesda, MD: National Cancer Institute; 2012.

[3] NCCN. Clinical practice guidelines in oncology: Bladder cancer. In: Editor, Book Clinical practice guidelines in oncology: Bladder cancer. Fort Washington, PA: NCCN; 2017.

[4] Christodouleas JP, Baumann BC, He J, et al. Optimizing bladder cancer locoregional failure risk stratification after radical cystectomy using SWOG 8710. Cancer. 2014;120:1272-80.

[5] Collaboration ABCM-a. Neoadjuvant chemotherapy in invasive bladder cancer: A systematic review and metaanalysis. Lancet. 2003;361:1927-34.

[6] Frazier HA, Robertson JE, Dodge RK, et al. The value of pathologic factors in predicting cancer-specific survival among patients treated with radical cystectomy for transitional cell carcinoma of the bladder and prostate. Cancer. 1993;71:3993-4001.

[7] Zehnder P, Studer UE, Skinner EC, et al. Super extended versus extended pelvic lymph node dissection in patients undergoing radical cystectomy for bladder cancer: A comparative study. J Urol. 2011;186:1261-8.

[8] Stein JP, Lieskovsky G, Cote R, et al. Radical cystectomy in the treatment of invasive bladder cancer: Long-term results in 1,054 patients. J Clin Oncol. 2001;19:666-75. 
[9] Hassan JM, Cookson MS, Smith JA, et al. Patterns of initial transitional cell recurrence in patients after cystectomy. J Urol. 2006;175:2054-7.

[10] Volkmer BG, Kuefer R, Bartsch GC, et al. Oncological followup after radical cystectomy for bladder cancer-is there any benefit? J Urol. 2009;181:1587-93; discussion 1593.

[11] International Collaboration of T, Medical Research Council Advanced Bladder Cancer Working P, European Organisation for $\mathrm{R}$, et al. International phase III trial assessing neoadjuvant cisplatin, methotrexate, and vinblastine chemotherapy for muscle-invasive bladder cancer: Long-term results of the BA06 30894 trial. J Clin Oncol. 2011;29:2171-7.

[12] Reddy AV, Pariser JJ, Pearce SM, et al. Patterns of failure after radical cystectomy for pt3-4 bladder cancer: Implications for adjuvant radiation therapy. Int J Radiat Oncol Biol Phys. 2016;94:1031-9.

[13] Pollack A, Zagars GK, Cole CJ, et al. The relationship of local control to distant metastasis in muscle invasive bladder cancer. J Urol. 1995;154:2059-63; discussion 2063-4.

[14] Ide H, Kikuchi E, Miyajima A, et al. The predictors of local recurrence after radical cystectomy in patients with invasive bladder cancer. Jpn J Clin Oncol. 2008;38:360-4.

[15] Baumann BC, Sargos P, Eapen LJ, et al. The rationale for post-operative radiation in localized bladder cancer. Bladder Cancer. 2017;3:19-30.

[16] Zaghloul MS, Awwad HK, Akoush HH, et al. Postoperative radiotherapy of carcinoma in bilharzial bladder: Improved disease free survival through improving local control. Int J Radiat Oncol Biol Phys. 1992;23:511-7.

[17] Zaghloul MS, Christodouleas JP, Smith A, et al. Adjuvant sandwich chemotherapy plus radiotherapy vs. adjuvant chemotherapy alone for locally advanced bladder cancer after radical cystectomy: A randomized phase 2 trial. JAMA Surg. 2018;153(1):e174591.

[18] Bilimoria KY, Stewart AK, Winchester DP, et al. The national cancer data base: A powerful initiative to improve cancer care in the united states. Ann Surg Oncol. 2008; 15:683-90.

[19] Haque W, Verma V, Butler EB, et al. Patterns of care and outcomes of multi-agent versus single-agent chemotherapy as part of multimodal management of low grade glioma. J Neurooncol. 2017;133:369-75.
[20] Haque W, Verma V, Fakhreddine M, et al. Addition of chemotherapy to definitive radiotherapy for ib1 and iial cervical cancer: Analysis of the national cancer data base. Gynecol Oncol. 2017;144:28-33.

[21] National Comprehensive Cancer Network. Bladder Cancer. Version 4.2017. https://www.nccn.org/professionals/ physician_gls/pdf/bladder.pdf. Accessed September 16, 2017.

[22] Brower JV, Chen S, Bassetti MF, et al. Radiation dose escalation in esophageal cancer revisited: A contemporary analysis of the national cancer data base, 2004 to 2012. Int J Radiat Oncol Biol Phys. 2016;96:985-93.

[23] Baumann BC, Guzzo TJ, He J, et al. A novel risk stratification to predict local-regional failures in urothelial carcinoma of the bladder after radical cystectomy. Int J Radiat Oncol Biol Phys. 2013;85:81-8.

[24] Solanki AA, Martin B, Korpics M, et al. Adjuvant radiotherapy use by us radiation oncologists after radical cystectomy for muscle-invasive bladder cancer. Clin Oncol (R Coll Radiol). 2017;29:429-35.

[25] Baumann BC, Guzzo TJ, He J, et al. Bladder cancer patterns of pelvic failure: Implications for adjuvant radiation therapy. Int J Radiat Oncol Biol Phys. 2013;85:363-9.

[26] Baumann BC, Bosch WR, Bahl A, et al. Development and validation of consensus contouring guidelines for adjuvant radiation therapy for bladder cancer after radical cystectomy. Int J Radiat Oncol Biol Phys. 2016;96:78-86.

[27] Orre M, Latorzeff I, Flechon A, et al. Adjuvant radiotherapy after radical cystectomy for muscle-invasive bladder cancer: A retrospective multicenter study. PLoS One. 2017;12(4):e0174978.

[28] Sui W, Lim EA, Joel Decastro G, et al. Use of adjuvant chemotherapy in patients with advanced bladder cancer after neoadjuvant chemotherapy. Bladder Cancer. 2017;3: 181-9.

[29] Seisen T, Jamzadeh A, Leow JJ, et al. Adjuvant chemotherapy vs observation for patients with adverse pathologic features at radical cystectomy previously treated with neoadjuvant chemotherapy. JAMA Oncol. 2017. 